\title{
Transcatheter aortic valve replacement for isolated aortic valve insufficiency: Experience with the Engager valve
}

\author{
Philipp Kiefer, MD, Joerg Seeburger, MD, PhD, Friedrich W. Mohr, MD, PhD, and \\ David M. Holzhey, MD, PhD, Leipzig, Germany
}

Since the introduction of transcatheter aortic valve replacement, numerous devices and access techniques have been developed and modified to address the treatment of aortic stenosis in high-risk patients. ${ }^{1}$ However, isolated aortic valve insufficiency has remained a controversial indication.

From the Department of Cardiac Surgery, University of Leipzig Heart Center, Leipzig, Germany.

Disclosures: Authors have nothing to disclose with regard to commercial support. Received for publication Aug 27, 2013; revisions received Nov 13, 2013; accepted for publication Nov 20, 2013; available ahead of print Jan 14, 2014.

Address for reprints: Philipp Kiefer, MD, Leipzig University Heart Center, Struempelstrasse 39, Leipzig 04289, Germany (E-mail: p.kiefer@med.uni-leipzig.de).

J Thorac Cardiovasc Surg 2014;147:e37-8 $0022-5223 / \$ 36.00$

Copyright (C) 2014 by The American Association for Thoracic Surgery http://dx.doi.org/10.1016/j.jtcvs.2013.11.035
We present the case of a 72-year-old woman (body mass index $19 \mathrm{~kg} / \mathrm{m}^{2}$ ) who was admitted to our hospital because of severe dyspnea (New York Heart Association functional class IV). Her medical history included breast cancer treated with mastectomy and radiotherapy followed by surgical myoplasty in 2004. Impaired lung function with a forced expiratory volume in 1 second of $30 \%$, mild renal insufficiency (creatinine $121 \mu \mathrm{mol} / \mathrm{L}$ ), high-grade peripheral arterial occlusive disease, and moderate pulmonary hypertension (pulmonary artery pressure, $51 \mathrm{~mm} \mathrm{Hg}$ plus central venous pressure) calculated her Society of Thoracic Surgeons score and log EuroSCORE 1 as 7.2 and 25.6, respectively. Transesophageal echocardiography revealed preserved left ventricular function (ejection fraction $65 \%$ ), moderate tricuspid and mitral insufficiency, severe aortic valve insufficiency with no calcification,

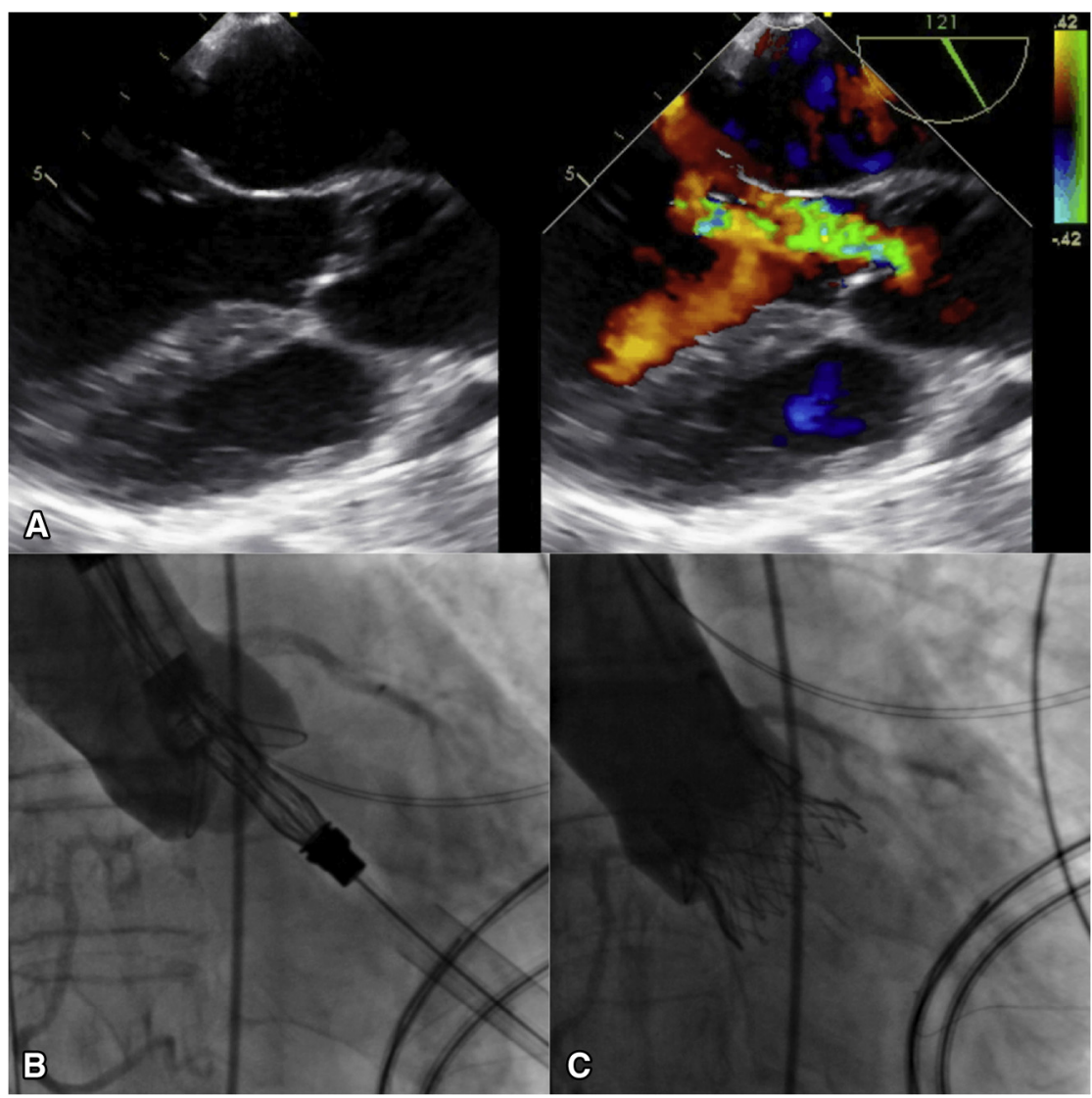

FIGURE 1. A, Transesophageal echocardiography, long axis view. B, Positioning and deployment of the Engager valve (Medtronic, Inc, Minneapolis, Minn). C, Final angiographic result showing no residual aortic regurgitation. 
and vena contracta of $0.6 \mathrm{~cm}$ (Figure 1, A). The aortic annulus was measured at $24 \mathrm{~mm}$. Preoperative computed tomography showed an effective aortic valve annulus of $24 \mathrm{~mm}$ and a perimeter of $80 \mathrm{~mm}$, the sinotubular size was $35 \mathrm{~mm}$, and the aortic bulge was described at 36 $\mathrm{mm}$. Because of her high perioperative risk and small, calcified femoral arteries, multidisciplinary team chose transapical aortic valve implantation. Owing to its positioning and anchoring facilities within the aortic root, the Engager valve (Medtronic, Inc, Minneapolis, Minn), with a size of $26 \mathrm{~mm}$ was chosen for implantation. The valve size was dependent on the annulus size, which was determined using both transesophageal echocardiography and computed tomography. Transapical access was achieved through left anterior minithoracotomy. After passing the native valve with the device, the arches were released and placed in the coronary sinuses (Figure 1, $B)$. Therefore, valve embolization into the left ventricle was almost impossible. By pulling the device slightly toward the left ventricle, the valve was finally released (Figure 1,C). The initial invasive measurement showed a trace residual aortic insufficiency and a peak gradient of $5 \mathrm{~mm} \mathrm{Hg}$. The mitral valve insufficiency immediately decreased from grade II to III to grade I.

The patient experienced atrioventricular blockage (grade III) and required pacemaker implantation but was discharged on postoperative day 12 .

\section{Reference}

1. Cribier A. Development of transcatheter aortic valve implantation (TAVI): a 20-year odyssey. Arch Cardiovasc Dis. 2012;105:146-52.

\title{
Direct aortic transcatheter aortic valve implantation for pure aortic valve regurgitation after implantation of a left ventricular assist device
}

\author{
René Krause, MD, Dietrich Metz, MD, and Hasan Bushnaq, MD, Halle, Germany
}

The increasing use of continuous-flow left ventricular assist devices (LVADs) for the purpose of destination therapy has led to associated secondary aortic valve insufficiency (AI) as a significant complication. ${ }^{1,2}$ Significant AI can lead to ineffective LVAD output and end-organ malperfusion, with consequent symptoms of congestive heart failure and significantly worse survival. ${ }^{3}$ The management of this condition is challenging.

\section{CLINICAL SUMMARY}

A 65-year-old woman with an LVAD was readmitted to our heart center because of recently increased shortness of breath at rest. The patient's medical history included ischemic cardiomyopathy, chronic obstructive pulmonary disease, pulmonary hypertension, moderate impaired renal function, and type II diabetes mellitus. Because of the

From the Department of Cardiac and Thoracic Surgery, Martin-Luther-University Halle-Wittenberg, Halle, Germany.

Disclosures: Hasan Bushnaq reports consulting fees from Medtronic and HeartWare. All other authors have nothing to disclose with regard to commercial support.

Received for publication Oct 20, 2013; revisions received Nov 23, 2013; accepted for publication Nov 29, 2013; available ahead of print Feb 2, 2014.

Address for reprints: Hasan Bushnaq, MD, Department of Cardiac and Thoracic Surgery, Martin-Luther-University Halle-Wittenberg, D-06097 Halle, Germany (E-mail: hasan.bushnaq@uk-halle.de).

J Thorac Cardiovasc Surg 2014;147:e38-41

$0022-5223 / \$ 36.00$

Copyright (C) 2014 by The American Association for Thoracic Surgery

http://dx.doi.org/10.1016/j.jtcvs.2013.11.039 end-stage ischemic cardiomyopathy with terminal heart failure (New York Heart Association class IV), she had undergone an LVAD implantation (HeartMate II; Thoratec Corporation, Pleasanton, Calif) from the left ventricular apex to the ascending aorta through a sternotomy in December 2009 (Figure 1).

Thereafter the patient recovered to a good general status. During the routine follow-ups in 2012, she reported increasing shortness of breath at daily activities. Echocardiography showed at this time a new finding of AI of grade II. Despite optimal medical therapy and LVAD adjustments, her symptoms remained. The repeated echocardiography after emergency admission showed moderate AI with volume overload of the left side of the heart as a result of a continuous AI during systole and diastole (Figure 2). The cusps and the annulus showed a mild degeneration as well as an altered coapting function. LVAD function was completely accurate. During hospitalization with optimal medical treatment, the patient's condition gradually deteriorated. She was therefore submitted for surgical treatment of the AI.

Because of the patient's poor general status, the multimorbidity and conducted heart surgery, we decided to attempt transcatheter aortic valve implantation (TAVI). The direct aortic access was chosen because of our previous good experiences with this procedure. In this case, it provided some advantages to the femoral access. 